\title{
NT-proBNP in Children With Left to Right Shunt and Dilated Cardiomyopathy
}

\author{
Hala Mahmoud Koura, ${ }^{1,}{ }^{*}$ Neamat M. Abdalla, ${ }^{2}$ Mona Hamed Ibrahim, ${ }^{3}$ Maha M. A. Abo Hashish, ${ }^{1}$ and \\ Sherif Mohamed Zaki ${ }^{4}$ \\ ${ }^{1}$ Department of Pediatrics, National Research Center, Cairo, Egypt \\ ${ }^{2}$ Atfal Misr Hospital, Cairo, Egypt \\ ${ }^{3}$ Clinical and Chemical Pathology Department, National Research Centre, Cairo, Egypt \\ ${ }^{4}$ Faculty of Medicine, Cairo University, Cairo, Egypt \\ "Corresponding author: Hala Mahmoud Koura, Pediatric Department, National Research Center, Cairo, Egypt. Tel: +20-23522317; +20-1122255757, E-mail: hala_koura@yahoo.com
}

Received 2015 October 23; Revised 2016 January 02; Accepted 2016 January 23.

\begin{abstract}
Background: B-type natriuretic peptide (BNP) levels are elevated in children with congenital heart disease involving a left-to-right shunt (LRS) and are also raised in dilated cardiomyopathy (DCM). As far as we know, there are few reports in the literature comparing the change of the NT-proBNP in LRS and DCM especially in the pediatric age group.

Objectives: The aim of the study was to compare the changes of the NT-proBNP in pediatric patients with LRS and DCM. Correlation between the levels of NT-proBNP and the echocardiographic parameters in both groups was determined.

Patients and Methods: A total of 30 children (13 males and 17 females) participated in the study. There were 11/30 (36.7\%) DCM and 19/30 (63.3\%) LRS. The control group consisted of 44 healthy infants and children. Manifestations of heart failure (decompensation) were recorded. The NT-pro BNP levels were measured. The following Echo parameters were assessed: systolic function (ejection fraction and fraction shortening), pulmonary to systemic flow (Qp/Qs) in LRS, pulmonary flow and pulmonary artery pressure(SPAP) and LV diastolic function (E-wave, A-wave, E/A ratio and deceleration time).

Results: Clinically $17 / 30$ (56.7\%) (11 of the LRS and 5 of the DCM) were decompensated. Significant shunt was present in $15 / 19$ (78.9\%) in LRS. Systolic dysfunction was presented in 5/30 (16.7\%) cases (4 patients were DCM and one case was LRS). Two types of diastolic dysfunction, impaired relaxation in 5/22 (22.7\%) patients and restrictive-like filling pattern in 5/16 (31.2\%) were observed. The NT-Pro BNP level was significantly elevated 11 and 16 times in the LRS and DCM groups respectively. Negative significant correlations were observed between the levels of NT-ProBNP and the following echo variables; EDD, LAD, E wave and E/A ratio in the LRS patients. Positive significant correlations were observed between the levels of NT-ProBNP and the following echo variables; PAP and QP/QS in the LRS. Both the PAP and QP/QS were higher in the elevated NT-Pro BNP group compared to the normal level group. The NT-Pro BNP level was elevated in all 17/30 (56.7\%) decompensated patients (11 were LRS, 6 were DCM) (P=0.002). However, the level was elevated in only $7 / 13$ (23.3\%) of the compensated patients ( 3 were LRS, 4 were DCM $(\mathrm{P}=0.002)$. The NT-Pro BNP level was also elevated in $18 / 19$ cases with pulmonary hypertension $(\mathrm{P}=0.01)$. Finally, we conclude that the NT-ProBNP level is elevated in both LRS and DCM in pediatric age. This elevation is more remarkable with heart failure and increased PAP in both diseased groups. The level was also elevated and correlated to Qp/Qs in the LRS patients.

Conclusions: So, we recommend the use of NT-ProBNP as a routine marker for following up patients with heart failure and pulmonary hypertension in LRS and DCM.
\end{abstract}

Keywords: NT-proBNP, LEFT to Right Shunt, Dilated Cardiomyopathy

\section{Background}

B-type natriuretic peptide (BNP) is a cardiac hormone secreted mainly by the ventricles in response to volume expansion and pressure load (1). Small amounts of a precursor protein, pro-BNP, are continuously produced by the heart. In reaction to stretch and tension of the myocardial wall, the pro-BNP is cleaved by corin enzyme into the active hormone BNP and an inactive fragment, NT-proBNP $(2,3)$.

Although BNP and NT-proBNP are synthesized in a 1:1 ratio, their plasma concentrations are different because of their different half-lives in vivo. BNP is cleared from the circulation by the natriuretic peptide $C$ receptor; whereas, NTproBNP is cleared by the kidneys (4). The half-life of BNP is 22 minutes, whereas the half-life of NT-ProBNP is $\sim 120 \mathrm{~min}$ - utes (5).

The BNP levels are known to be elevated in patients with symptomatic left ventricular dysfunction and may reflect diastolic dysfunction $(6,7)$. Though BNP has emerged as a sensitive biochemical marker for cardiac dysfunction in adults, limited data suggest similar properties in pediatric patients $(8,9)$.

BNP levels are elevated in children with congenital heart disease involving a left-to-right shunt (LRS), and are correlated with the shunt volume (10). BNP levels are also raised in dilated cardiomyopathy (DCM) (11). As far as we know, there are few reports in the literature comparing the change of the NT-ProBNP in LRS and DCM especially in the pediatric age group. 


\section{Objectives}

the aim of the present study was to compare the changes of the plasma NT-ProBNP in pediatric patients with LRS and DCM and to correlate its level with the echocardiographic parameters in both groups.

\section{Patients and Methods}

This study was a cross sectional (comparative) study where 30 children (13 males and 17 females) were recruited from the pediatric cardiology clinic, Atfal Misr hospital, ministry of health, Cairo, Egypt. Their age was $4.1 \pm 0.79$ ( 0.16 - 12) years. $11 / 30(36.7 \%)$ patients had DCM and 19/30 (63.3\%) had LRS. 16/30 (53.3\%) had VSD, 2/30 (6.7\%) PDA and 1/30(3.3\%) VSD and PDA (Table 1). Any child with associated valve insufficiency, outflow tract obstruction, complex congenital heart disease (e.g. VSD + PS or VSD + TGA) or with known chromosomal abnormalities was excluded from the study. Also, any child with an associated illness such as water and electrolyte imbalance, neoplastic disease, liver disease or renal disease was excluded.

The control group consisted of 44 healthy infants and children matched for age and sex. These children had normal physical examination and laboratory findings. The control group was used to assess the plasma level of NTproBNP which was considered as a reference for the normal values as these values vary according to age and sex $(12,13)$.

All procedures were carried out in accordance with the Declaration of Helsinki 1975, revised 1983. Informed consent was obtained from the parents of the children according to the guidelines of the ethical committee of NRC, Dokki, Egypt.

All the studied patients were subject to a thorough clinical evaluation including:

- Detailed history and complete physical examination.

- Clinical manifestations of heart failure (decompensation) which was considered positive if two of the following criteria were fulfilled: (i) reduced physical activity or exercise capacity; (ii) feeding difficulties including prolonged feeds, frequent feeds or failure to thrive; (iii) dyspnea on physical exercise; (iv) tachypnea at rest; (v) hepatomegaly; and (vi) edema (14).

- Full echocardiographic evaluation using two dimensional transthoracic echocardiographic and Doppler (Philips iE33 echo machine) studies in the left lateral decubitus position from multiple windows.

- Concerning the properties of Doppler assessment, we had eight controls which were divided into three categories. The first was the group of controls that influence the quality of the Doppler recording (Doppler gain, gray scale, and wall filter). This group was of importance in both

\begin{tabular}{|c|c|}
\hline Variable & No. (\%) \\
\hline \multicolumn{2}{|l|}{ Groups } \\
\hline DCM & $11(36.7)$ \\
\hline LRS & $19(63.3)$ \\
\hline VSD & $16(53.3)$ \\
\hline PDA & $2(6.7)$ \\
\hline VSD and PDA & $1(3.3)$ \\
\hline \multicolumn{2}{|l|}{ Sex } \\
\hline Male & $13(43.3)$ \\
\hline Female & $17(56.7)$ \\
\hline \multicolumn{2}{|l|}{ Clinically } \\
\hline Compensated & $13(43.3)$ \\
\hline LRS & $8(26.7)$ \\
\hline DCM & $5(16.7)$ \\
\hline Decompensated & $17(56.7)$ \\
\hline LRS & $11(36.7)$ \\
\hline DCM & $6(20.0)$ \\
\hline \multicolumn{2}{|l|}{ Significant shunt (LRS) } \\
\hline Significant shunt & $15(78.9)$ \\
\hline Compensated & $7(36.8)$ \\
\hline Decompensated & $8(42.1)$ \\
\hline Non-significant shunt & $4(21.1)$ \\
\hline Compensated & $1(5.3)$ \\
\hline Decompensated & $3(15.8)$ \\
\hline
\end{tabular}

pulsed waved (PW) and continuous wave (CW) examinations. The second group was the controls that change the appearance of the graphic display (scale factor and baseline position) and also applied to both CW and PW examinations. The third group was of use only for PW Doppler since they relate to the sample volume (cursor, sample depth and angle) (15).

- Observer bias can arise from a variety of causes and may potentially alter physician's judgments of subjective data (16). All echocardiograms were interpreted by experienced cardiologist who was blinded to the NT-proBNP level to eliminate the observer bias.

- The following Echo parameters were assessed:

- Systolic function: ejection fraction and fraction shortening (EF\% and FS \%). Systolic dysfunction was defined by an ejection fraction $<50 \%(14)$.

- Left ventricular interventricular septum (IVS), posterior wall thickness (PWT) and right ventricular dimension (RVD). 
- Left ventricular end systolic and diastolic diameters (ESD and EDD).

- Left atrial and left ventricular dimensions were measured from M-mode images (17).

- Left atrial dimension (LAD), aortic root dimension (AOD) and left atrial to aortic root dimension (LAD/AOD) ratios were measured. $\mathrm{LAD} / \mathrm{AOD}$ ratio is an index of volume load in LRS and index of left atrial dilatation in DCM (18).

- Pulmonary to systemic flow (Qp/Qs) ratio was measured using Doppler velocimetry and two-dimensional echocardiography. A Qp/Qs ratio > 1.5 indicated the presence of a significant shunt (15).

- Pulmonary flow (P flow) and systolic pulmonary artery pressure (SPAP) were measured using Doppler velocimetry. Pulmonary venous systolic and diastolic flow velocities were obtained as the maximal values reached during the respective phase of the cardiac cycle, and the pulmonary venous "A" reversal was the maximal velocity of retrograde flow into the vein after the $\mathrm{P}$ wave of the ECG (15). Pulmonary hypertension is defined as a resting mPAP $>25 \mathrm{mmHg}(19)$.

- The velocity of the tricuspid regurgitation (TR) jet was measured with continuous-wave Doppler echocardiography.

- LV diastolic function (20): with Doppler echo to study the mitral flow velocity in order to assess LV filling (diastolic function) by the following measurements:

1) E-wave (early filling phase)

2) A-wave (late or atrial filling phase)

3) E/A ratio

4) Deceleration time (DT)

- Diastolic dysfunction was classified in 3 categories:

1) Impaired relaxation (an E/A ratio $<1$ or DT $>240 \mathrm{~ms}$ )

2) Pseudonormal (an E/A ratio of 1 to 1.5 and DT $>240$ $\mathrm{ms}$ )

3) Restrictive like filling patterns ( DT $<160 \mathrm{~ms}$ with $\geq$ 1 of the following: left atrial size $>5 \mathrm{~cm}, \mathrm{E} / \mathrm{A}>1.5)(20)$.

\subsection{Blood Sampling and Assay for NT-Pro BNP}

Blood samples were collected after the echocardiogram record. Initially, a routine blood analysis was performed in all subjects to rule out organic lesions, infections, electrolytic disorders, liver and kidney disease. Blood ( $5 \mathrm{~mL}$ ) was drawn from a peripheral vein. The blood specimens were left at room temperature to clot and sera were separated into aliquots with proper and unique identification. Quantitative assessment of NT-ProBNP was performed using CLOUD CLONE CORP. ELISA kit supplied by USCN LFE Science INC. USA Cat No SEA485HU. This Elisa kit implies a sandwich technique in which the microtiter plate is precoated with an antibody specific to NT-ProBNP. Another biotin conjugated antibody specific to NT-ProBNP is added to samples and standards. A change in color is exhibited only in wells containing NT-Pro BNP, biotin antibody and enzyme conjugated avidin. The color intensity developed is directly proportional to the amount of NTProBNP in the wells (21).

\subsection{Statistical Analysis}

The data were collected and studied using SPSS 20 statistical program. The mean, standard deviation (SD), minimum, maximum and range were calculated for all quantitative variables. The quantitative data were examined by Kolmogrov Smirnov test for normality.

Comparison between the means of the different echocardiographic variables was done on the basis of the diseased groups and also on the basis of the elevated level of the NT-ProBNP using the Student independent t test. Also, comparison between the means of the NT-ProBNP among the different groups was done using one way ANOVA test.

$\mathrm{Q}$ square $\left(\mathrm{X}^{2}\right)$ test was used to study the association between the diseased groups and the cardiac dysfunctions. The test was also used to study the association between the NT-Pro BNP and the different variables in the diseased groups.

Correlation between NT-ProBNP and the different echocardiographic variables in the diseased groups was determined using Pearson's correlation test.

Level of significance was considered at P value $<0.05$ in all tests.

\section{Results}

Clinically 17/30 (56.7\%) (11 LRS and 5 DCM) were decompensated, while 13/30 (43.3\%) (8 LRS and 5 DCM) were compensated. $15 / 19$ (78.9\%) of the LRS patients had a significant shunt (7 patients were compensated and 8 patients were decompensated) (Table 1).

The EDD, ESD, PWT, LAD and LAD/AOD ratio were significantly higher in the DCM group as compared to their similarities in the LRS group. However, the EF (\%) and P flow ( $\mathrm{mmHg}$ ) were significantly higher in the LRS group as compared with the DCM group (Figure 1).

$5 / 30(16.7 \%)$ cases had systolic dysfunction. Four (13.3\%) patients had DCM and one $(3.3 \%)$ case had LRS $(\mathrm{P}=0.04)$. Two types of diastolic dysfunction were observed in the present study; impaired relaxation and restrictive-like filling pattern. They were observed in 10 patients. 5/22 (22.7\%) patients had impaired relaxation and 5/16 (31.2\%) had restrictive-like filling pattern. The distribution in the both diastolic dysfunction patterns was 4 cases with LRS and one case with DCM (Table 2 and Figure 2). The diastolic 

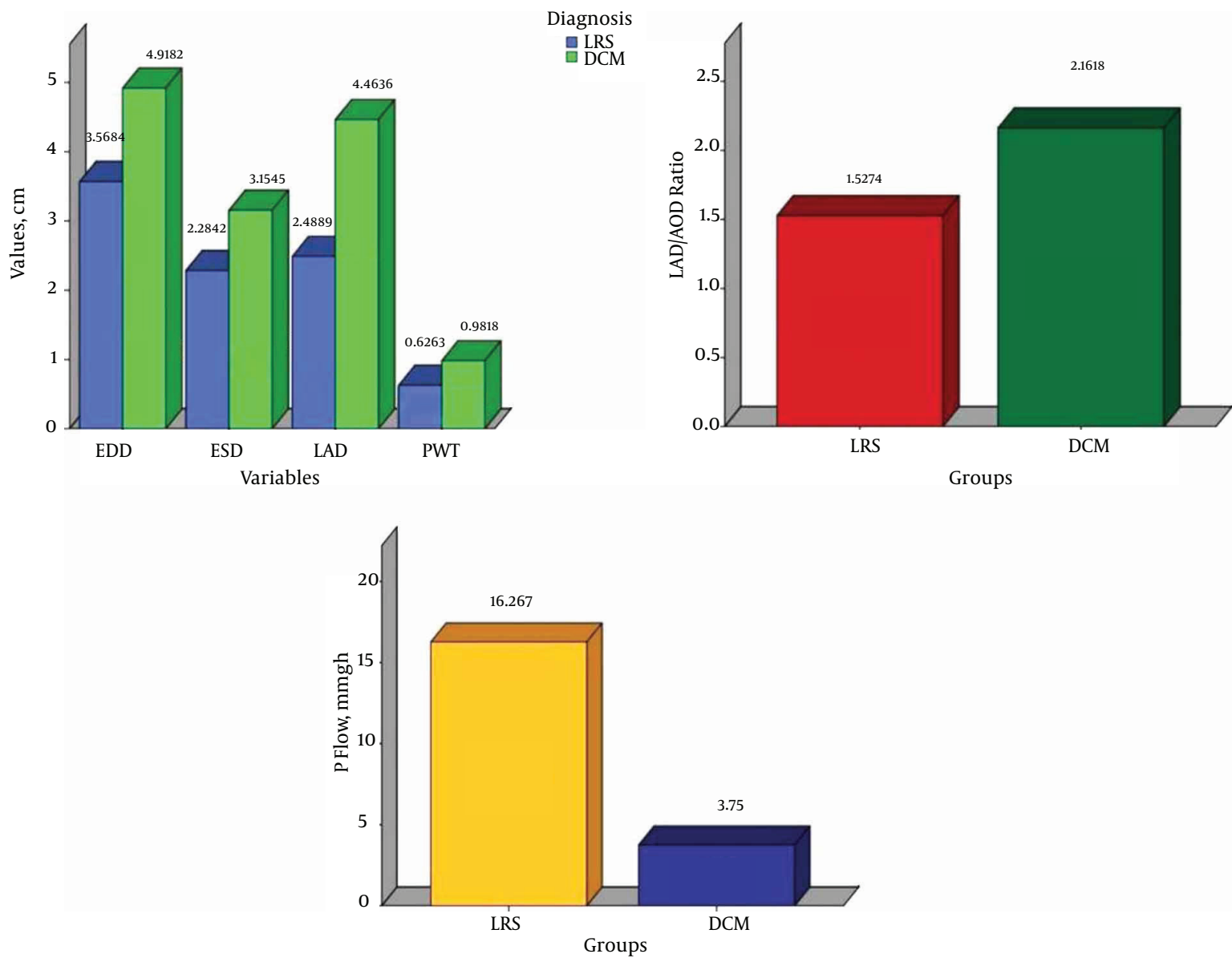

Figure 1. Comparison Between the Mean ECD, ESD, LAD, PWT, LAD/AOD Ratios and P Flow (mmgh) of the Diseased Groups

dysfunction was measured in 22 patients only, of them, the DT couldn't be measured in 6 cases. So, the total number of cases in the Pseudonormal and Restrictive like types was 16 cases only.

Concerning the association between the ventricular dysfunction and the level of the NT-ProBNP, it was observed that the level of the marker was elevated in $4 / 5$ (80\%) cases of the systolic dysfunction, in 3/5 (60\%) cases of the restrictive-like filling and finally in all (100\%) cases of the impaired relaxation pattern (Figure 2).

Concerning the level of NT-proBNP in the different age groups, the patients were divided into 4 groups according to their ages: 0 - 1 year, $>1-5$ years, $>5-10$ years and lastly $>$ 10 years. Figure 3 illustrated a significant difference in the level of the NT-Pro BNP between the different age groups in patients with LRS $(\mathrm{P}=0.04)$; where there is a decreasing level of the NT-proBNP as the child gets older. The same figure revealed that above the age of ten years, the NT-ProBNP was significantly higher in patients of DCM $(\mathrm{P}=0.03)$.

The NT-ProBNP level was significantly elevated 11 and 16 times in the LRS and DCM groups respectively as compared with that of the control group. Non-significant change was observed between the LRS and DCM patients (Table 3).

The NT-ProBNP level was elevated in all (17/17) 17 decompensated patients, i.e., 100\% (11 had LRS, 6 had DCM) $(\mathrm{P}=$ $0.002)$. However, the level was elevated in only $7 / 13$ (53\%) of the compensated patients ( 3 patients had LRS, 4 patients had DCM $)(P=0.002)$ (Figure 4). Also, the NT-Pro BNP level was elevated in 18/19 cases with pulmonary hypertension , while in only one case with pulmonary hypertension the level of the NT-Pro BNP level was normal $(\mathrm{P}=0.01)$ (Table 4 and Figure 4).

Negative significant correlation was observed between the levels of NT-Pro BNP and the following echo variables; EDD, LAD, E wave and E/A ratio in the LRS patients. Conversely, positive significant correlation was observed be- 
Table 2. Association Between Disease Groups and Cardiac Dysfunctions ${ }^{\mathrm{a}}$

\begin{tabular}{|c|c|c|c|c|}
\hline \multirow[t]{2}{*}{ Category } & \multicolumn{2}{|c|}{ Disease Groups } & \multirow[t]{2}{*}{ Total } & \multirow[t]{2}{*}{ Significance } \\
\hline & LRS & DCM & & \\
\hline Systolic function & & & & $0.04^{\mathrm{b}}$ \\
\hline Normal & $18(60.0)$ & $7(23.3)$ & $25(83.3)$ & \\
\hline Systolic dysfunction & $1(3.3)$ & $4(13.3)$ & $5(16.7)$ & \\
\hline Impaired Relaxation $^{c}$ & & & & 0.8 \\
\hline No & $13(59.1)$ & $4(18.2)$ & $17(77.3)$ & \\
\hline Yes & $4(18.2)$ & $1(4.5)$ & $5(22.7)$ & \\
\hline Pseudonormal $^{\mathrm{d}}$ & & & & - \\
\hline No & $11(68.8)$ & $5(31.2)$ & $16(100)$ & \\
\hline Yes & $0(0.0)$ & $0(0.0)$ & $0(0.0)$ & \\
\hline Restrictive like $^{d}$ & & & & 0.5 \\
\hline No & $7(43.8)$ & $4(25.0)$ & $11(68.8)$ & \\
\hline Yes & $4(25.0)$ & $1(6.2)$ & $5(31.2)$ & \\
\hline
\end{tabular}

${ }^{\mathrm{a}}$ Values are expressed as No. (\%).

${ }^{\mathrm{b}}$ Statistically significant.

${ }^{\mathrm{C}}$ Impaired relaxation was measured in 22 patients.

${ }^{\mathrm{d}}$ The DT couldn't be measured in 6 cases. So, the total number of cases in the pseudonormal and restrictive like was 16 cases.

A

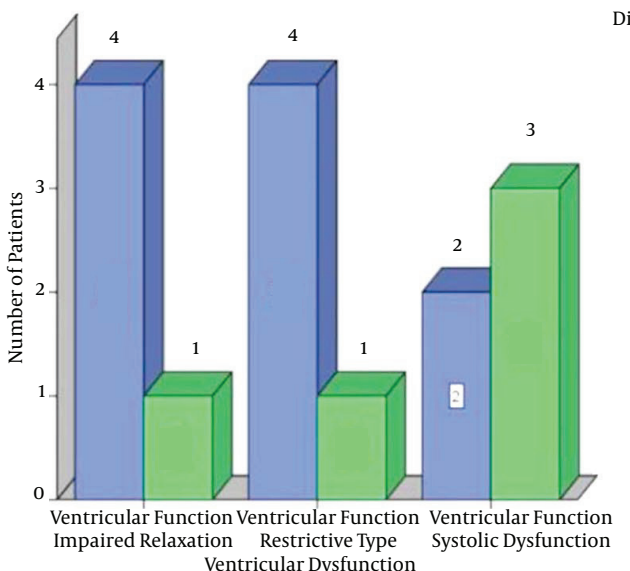

B

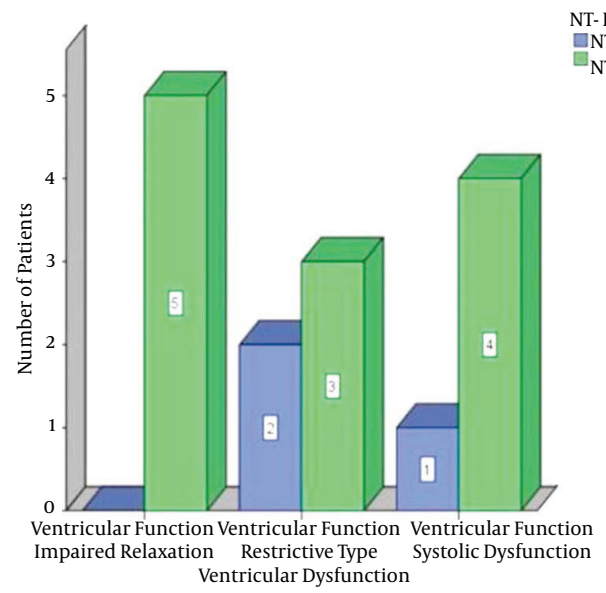

Figure 2. A, association between ventricular dysfunction and the diseased groups; B, association between ventricular dysfunction and the elevated NT-ProBNP

Table 3. Comparison of Mean and SD of the NT-Pro BNP Among the Different Groups ${ }^{\mathrm{a}}$

\begin{tabular}{|c|c|c|c|c|c|c|}
\hline & Control & LRS & DCM & P1 (LRS Versus Control) & P2 (DCM Versus Control) & P3 ( DCM Versus LRS) \\
\hline NT-Pro BNP & $20.73 \pm 6.50$ & $229.84 \pm 181.81$ & $238.36 \pm 149.07$ & $0.000^{\mathrm{b}}$ & $0.000^{\mathrm{b}}$ & 1.00 \\
\hline
\end{tabular}

${ }^{\mathrm{a}}$ Values are expressed as mean $\pm \mathrm{SD}$

${ }^{\mathrm{b}}$ Statistically significant. 


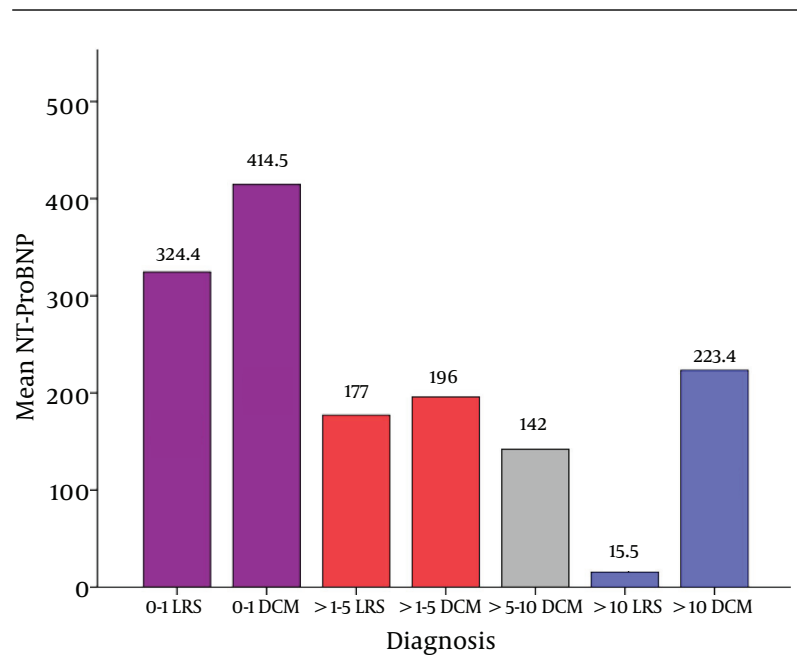

Figure 3. Comparison Between Mean NT-ProBNP of the LRS and DCM Groups, in Different Patients' age Groups

Table 4. Comparison Between Mean Echocardiographic Variables on the Basis of the NT-Pro BNP ${ }^{\mathrm{a}}$

\begin{tabular}{|lccc}
\hline Variable & $\begin{array}{c}\text { Normal NT-Pro BNP } \\
\text { Patients }(\mathbf{n}=\mathbf{6})\end{array}$ & $\begin{array}{c}\text { Elevated NT-Pro } \\
\text { BNP Patients }(\mathbf{n}= \\
\mathbf{2 4})\end{array}$ & PValue \\
\hline IVS, cm & $.0704 \pm 0.13$ & $.66 \pm 0.19$ & 0.843 \\
\hline EDD, cm & $4.08 \pm 1.34$ & $4.06 \pm 1.28$ & 0.966 \\
\hline ESD, cm & $2.68 \pm 1.10$ & $2.58 \pm 1.13$ & 0.847 \\
\hline PWT, cm & $0.63 \pm .16$ & $.79 \pm 0.51$ & 0.475 \\
\hline FS, \% & $33.50 \pm 6.95$ & $36.04 \pm 11.69$ & 0.616 \\
\hline EF, \% & $63.83 \pm 11.27$ & $62.83 \pm 13.58$ & 0.869 \\
\hline LAD, cm & $3.18 \pm 0.81$ & $3.25 \pm 1.66$ & 0.923 \\
\hline AOD, cm & $1.98 \pm 0.78$ & $1.77 \pm 0.44$ & 0.545 \\
\hline LAD/AOD & $1.70 \pm 0.33$ & $1.77 \pm 0.76$ & 0.8 \\
\hline E wave, M/S & $1.08 \pm 0.13$ & $0.94 \pm 0.29$ & 0.378 \\
\hline A wave & $0.70 \pm 0.29$ & $0.77 \pm 0.28$ & 0.171 \\
\hline E/A ratio & $1.87 \pm 1.17$ & $1.36 \pm 0.62$ & 0.219 \\
\hline DT, ms & $127.33 \pm 17.62$ & $121.38 \pm 42.23$ & 0.818 \\
\hline TR, mmHg & $40.17 \pm 12.97$ & $49.13 \pm 19.75$ & 0.305 \\
\hline P flow, mmHg & $11.00 \pm 7.81$ & $14.13 \pm 8.58$ & 0.566 \\
\hline PAP, mmHg & $18.33 \pm 10.80$ & $2.64 \pm 1.30$ & $0.01^{\mathrm{b}}$ \\
\hline QP /QS, LRS & $2.00 \pm 0.00$ & $0.000^{\mathrm{b}}$ \\
\hline RVD, cm & $2.67 \pm 0.68$ & 0.448 \\
\hline balues are expressed as mean $\pm \mathrm{SD}$. & & \\
\hline
\end{tabular}

tween the level of NT-Pro BNP and the following echo variables: PAP and the QP/QS in patients of the same group (Figure 5). Both the PAP and the QP/QS were higher in the elevated NT-Pro BNP group compared to the normal level group patients $(\mathrm{P}<0.05)$ (Table 4$)$.

\section{Discussion}

In the present study, the NT-Pro BNP level was elevated in $24 / 30(80 \%)$ ( 14 of the LRS and 10 of the DCM). Many authors described the elevation of the NT-Pro BNP level in children with LRS and DCM $(10,11)$.

The NT-Pro BNP level was elevated in 14/19 (73.6\%) of the LRS. The level of the NT-Pro BNP was 11 times higher in the LRS children as compared to that of the control group ( $P$ $=0.000)$. The higher levels of the NT-Pro BNP in children with LRS than that in healthy children indicate that BNP reflects a significant load on the heart (10). This is proved in our study by significantly high pulmonary flow in this group. In addition, the LAD/AOD ratio is significantly high in this group which is used as an index of volume load in LRS (18).

Ten out of the previously mentioned 14 LRS cases $(52.6 \%$ of the total LRS) had significant shunt (QP/QS > 1.5); while in the remaining 4 cases (21.1\% of the total LRS) had nonsignificant shunt. The mean $\mathrm{QP} / \mathrm{QS}$ was generally elevated $(2.47 \pm 1.15)$. The BNP is released by the ventricular myocytes in response to left ventricular volume overload as a result of significant left-to-right shunt (22).

A strong significant positive correlation between the concentration of the NT-ProBNP and the Qp/Qs was observed in the present study $(\mathrm{r}=0.5$ and $\mathrm{P}=0.02)$ reflecting the shunt size of LRS and the volume load in the pulmonary artery and right ventricle $(23,24)$. Therefore, the level of the NT-Pro BNP may have a role in quantifying the severity of the LRS (22).

The NT-ProBNP level was elevated in 10/11 DCM which was $90.9 \%$ of the total DCM. The level significantly elevated 16 times higher than the control group. This was in keeping with authors who reported that the NT-ProBNP levels are generally raised in all types of cardiomyopathies: dilated, hypertrophic, and restrictive (11). However, its elevation above the LRS patients was insignificant which may be attributed to small number of the studied cases.

Children with LRS may progress to develop decompensated heart failure. Also, heart failure is a major complication in cardiomyopathies (25). In our study, 11/19 LRS cases (57.9\% of the total LRS) and 6/11 DCM cases (54.5\% of the total DCM) were clinically decompensated. All the decompensated cases were associated with elevated NT-ProBNP levels. Many authors reported elevation of the NT-ProBNP 

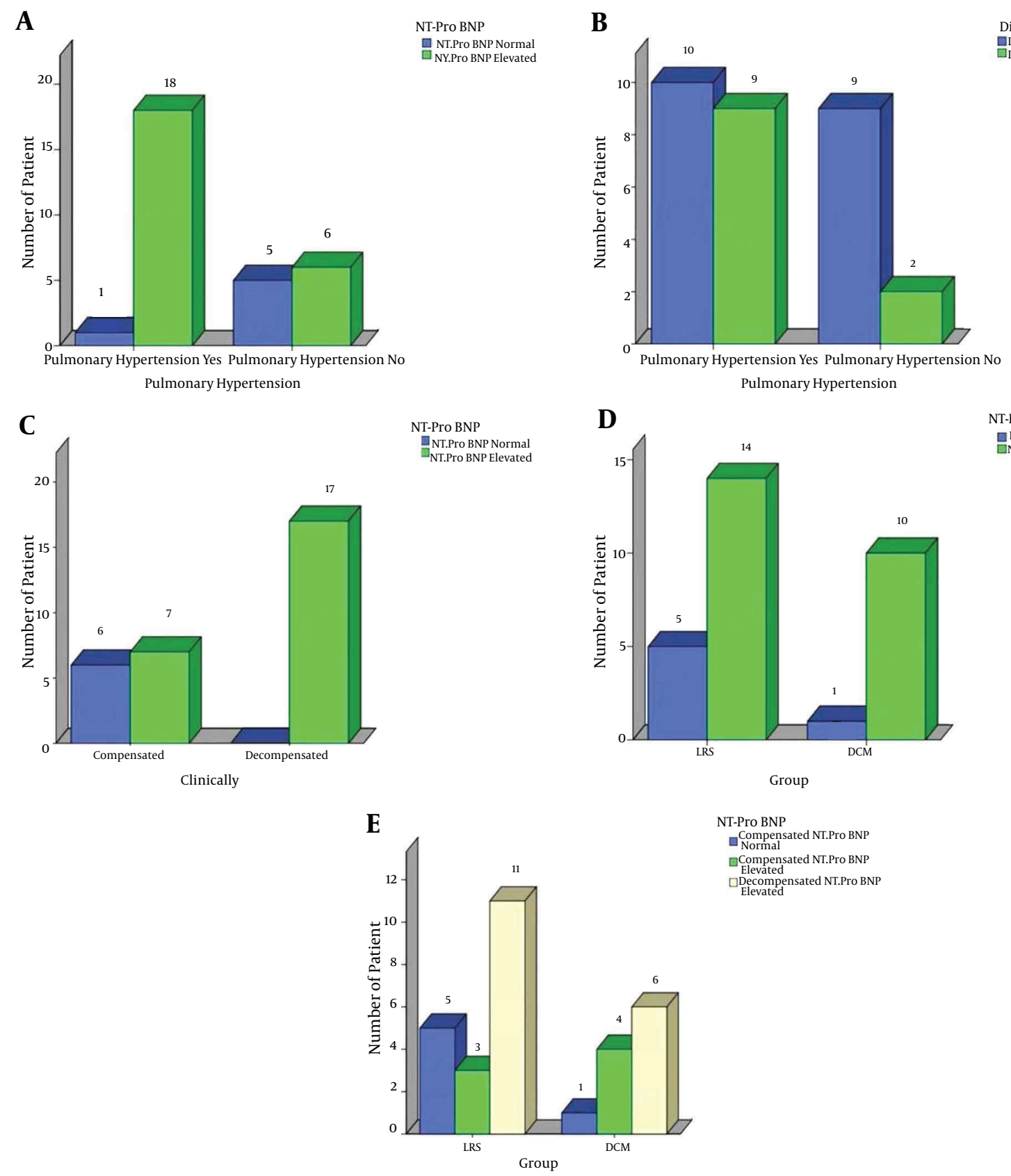

$$
\begin{aligned}
& \text { NT-Pro BNP } \\
& \quad \text { Compensated NT.Pro BNP } \\
& \text { Normal } \\
& \text { Compensated NT.Pro BNP } \\
& \text { Elevated } \\
& \text { Decompensated NT.Pro BNP } \\
& \text { Elevated }
\end{aligned}
$$



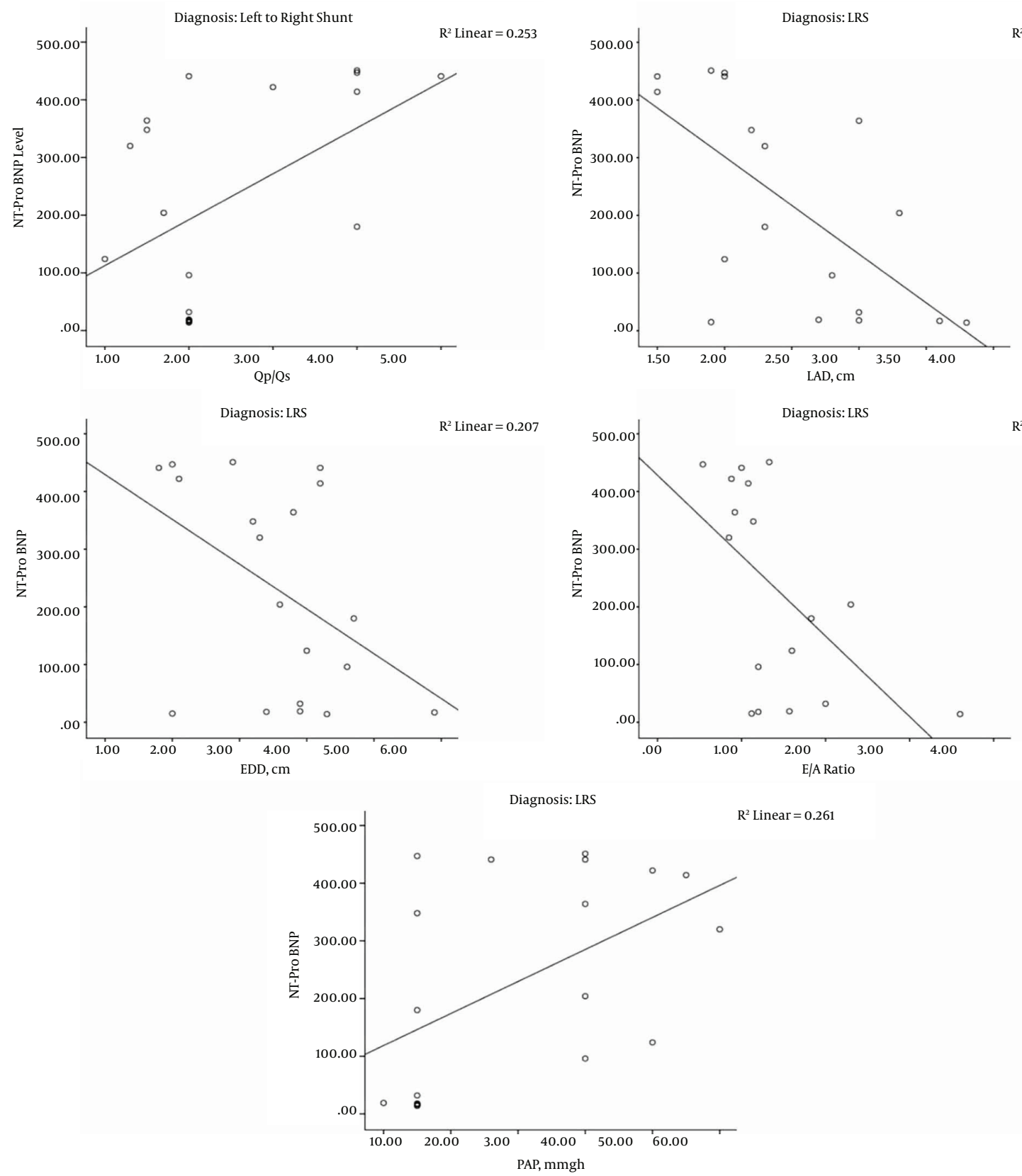

Figure 5. Scatter Plot Showing the Correlation Between the Levels of NT-Pro BNP and the Following Echo Variables; QP/QS, LAD, E/A Ratio and PAP in the LRS Patients

We found that $5 / 30(16.7 \%)$ cases had systolic dysfunction. Four (13.3\%) patients had DCM and one (3.3\%) case had LRS. The level of the NT-ProBNP was elevated in $4 / 5(80 \%)$ cases of the systolic dysfunction. Many authors suggested the use of the NT-ProBNP as a method of screening for leftventricular systolic dysfunction in the general population (29).
The NT-ProBNP provides positive evidence of the presence of diastolic dysfunction (30). Two types of diastolic dysfunction were observed in the present study; impaired relaxation and restrictive-like filling pattern. They were observed in 10 patients. 5/22 (22.7\%) patients had impaired relaxation and 5/16 (31.2\%) had restrictive-like filling pattern. The distribution in both diastolic dysfunction patterns was 
4 cases with LRS and one case with DCM. NT-ProBNP level was elevated in $3 / 5$ (60\%) cases of the restrictive-like filling and in all (100\%) cases of the impaired relaxation pattern. This was in keeping with some authors who reported the elevation of NT-ProBNP in patients with impaired relaxation and restrictive filling pattern (20).

Also, the NT-ProBNP level was elevated in almost all (18/19) cases with pulmonary hypertension. The elevation in the BNP level is usually not seen until PAP is high enough to cause right ventricular strain (31) which explains absence of high PAP in the remaining (1/19) case.

As previously described by some authors (31), a positive significant correlation was observed in the presents study between the elevated level of the NT-ProBNP and the $\operatorname{PAP}(\mathrm{P}=0.01)$. This correlation was more obvious and significant in LRS patients than in DCM patients. The risk of pulmonary hypertension is increased with connective tissue disease, portal hypertension, congenital LRS, or a family history of idiopathic pulmonary arterial hypertension (32).

We also found that the level of NT-ProBNP decreases as the child gets older in the LRS patients. This finding alerts us for an early diagnosis of LRS with subsequent earlier detection of the elevated NT-ProBNP level in an attempt to give an early proper medical care to preserve the normal cardiac state. No such studies were done in these pediatric age groups as all the reported studies were concerned with older ages $(12,13)$.

Finally, we conclude that the NT-ProBNP level is elevated in both LRS and DCM in pediatric age. This elevation is more remarkable with heart failure and increased PAP in both diseased groups. The level was also elevated and correlated to Qp/Qs in the LRS patients.

So, we recommend the use of NT-ProBNP as a routine marker for following up patients with heart failure and pulmonary hypertension in LRS and DCM.

\section{References}

1. Cowie MR, Mendez GF. BNP and congestive heart failure. Progress Cardiovasc Dis. 2002;44(4):293-321.

2. Pfister R, Schneider CA. Natriuretic peptides BNP and NT-proBNP: established laboratory markers in clinical practice or just perspectives?. Clin Chim Acta. 2004;349(1-2):25-38. doi: 10.1016/j.cccn.2004.06.018. [PubMed: 15469852].

3. Hammerer-Lercher A, Puschendorf B, Mair J. Cardiac natriuretic peptides: new laboratory parameters in heart failure patients. Clin Lab. 2001;47(5-6):265-77. [PubMed: 11405605].

4. McCullough PA, Omland T, Maisel AS. B-type natriuretic peptides: a diagnostic breakthrough for clinicians. Rev Cardiovasc Med. 2003;4(2):72-80. [PubMed: 12776016].

5. Kemperman H, van den Berg M, Kirkels H, de Jonge N. B-type natriuretic peptide (BNP) and N-terminal proBNP in patients with endstage heart failure supported by a left ventricular assist device. Clin Chem. 2004;50(9):1670-2. doi: 10.1373/clinchem.2003.030510. [PubMed: 15331503].
6. Maeda K, Tsutamoto T, Wada A, Hisanaga T, Kinoshita M. Plasma brain natriuretic peptide as a biochemical marker of high left ventricular end-diastolic pressure in patients with symptomatic left ventricular dysfunction. Am Heart J. 1998;135(5 Pt 1):825-32. [PubMed: 9588412].

7. Cheung BM. Plasma concentration of brain natriuretic peptide is related to diastolic function in hypertension. Clin Exp Pharmacol Physiol. 1997;24(12):966-8. [PubMed: 9406666].

8. Baughman KL. B-type natriuretic peptide - a window to the heart. $N$ Engl J Med. 2002;347(3):158-9. doi: 10.1056/NEJMp020057. [PubMed: 12124403].

9. Suda K, Matsumura M, Matsumoto M. Clinical implication of plasma natriuretic peptides in children with ventricular septal defect. Pediatr Int. 2003;45(3):249-54. [PubMed: 12828576].

10. Kavga M, Varlamis G, Giannopoulos A, Papadopoulou-Legbelou K, Varlamis S, Bompotis $\mathrm{G}$, et al. Correlation of plasma B-type natriuretic peptide with shunt volume in children with congenital heart disease involving left-to-right shunt. Hellenic J Cardiol. 2013;54(3):192-8. [PubMed: 23685656].

11. Maisel AS, Koon J, Krishnaswamy P, Kazenegra R, Clopton P, Gardetto $\mathrm{N}$, et al. Utility of B-natriuretic peptide as a rapid, point-of-care test for screening patients undergoing echocardiography to determine left ventricular dysfunction. Am Heart J. 2001;141(3):367-74. doi: 10.1067/mhj.2001.113215. [PubMed: 11231433].

12. Redfield MM, Rodeheffer RJ, Jacobsen SJ, Mahoney DW, Bailey KR, Burnett JJ. Plasma brain natriuretic peptide concentration: impact of age and gender. J Am Coll Cardiol. 2002;40(5):976-82. [PubMed: 12225726].

13. Wang TJ, Larson MG, Levy D, Leip EP, Benjamin EJ, Wilson PW, et al. Impact of age and sex on plasma natriuretic peptide levels in healthy adults. Am J Cardiol. 2002;90(3):254-8. [PubMed: 12127613].

14. Westerlind A, Wahlander H, Lindstedt G, Lundberg PA, Holmgren D. Clinical signs of heart failure are associated with increased levels of natriuretic peptide types $B$ and A in children with congenital heart defects or cardiomyopathy. Acta Paediatr. 2004;93(3):340-5. [PubMed: 15124836].

15. Driscoll DJ. 2013 College of Diplomates of the American Board of Pediatric Dentistry Annual Meeting: pediatric cardiology: an overview. Pediatr Dent. 2013;35(5):E137-47. [PubMed: 24436998].

16. Tighe JJ, Steiman DM, Vernalis MN, Taylor AJ. Observer bias in the interpretation of dobutamine stress echocardiography. Clin Cardiol. 1997;20(5):449-54. [PubMed: 9134276].

17. Lubien E, DeMaria A, Krishnaswamy P, Clopton P, Koon J, Kazanegra R, et al. Utility of B-natriuretic peptide in detecting diastolic dysfunction: comparison with Doppler velocity recordings. Circulation. 2002;105(5):595-601. [PubMed: 11827925].

18. Kayar A, Gonul R, Or ME, Uysal A. M-mode echocardiographic parameters and indices in the normal German shepherd dog. Vet Radiol Ultrasound. 2006;47(5):482-6. [PubMed: 17009513].

19. Casserly B, Klinger JR. Brain natriuretic peptide in pulmonary arterial hypertension: biomarker and potential therapeutic agent. Drug Des Devel Ther. 2009;3:269-87. [PubMed: 20054445].

20. Yu CM, Sanderson JE, Shum IO, Chan S, Yeung LY, Hung YT, et al. Diastolic dysfunction and natriuretic peptides in systolic heart failure. Higher ANP and BNP levels are associated with the restrictive filling pattern. Eur Heart J. 1996;17(11):1694-702. [PubMed: 8922918].

21. Mueller T, Gegenhuber A, Poelz W, Haltmayer M. Diagnostic accuracy of B type natriuretic peptide and amino terminal proBNP in the emergency diagnosis of heart failure. Heart. 2005;91(5):606-12. doi: 10.1136/hrt.2004.037762. [PubMed: 15831643].

22. Davis GK, Bamforth F, Sarpal A, Dicke F, Rabi Y, Lyon ME. B-type natriuretic peptide in pediatrics. Clin Biochem. 2006;39(6):600-5. doi: 10.1016/j.clinbiochem.2005.12.004. [PubMed: 16430880].

23. Cantinotti M, Passino C, Storti S, Ripoli A, Zyw L, Clerico A. Clinical relevance of time course of BNP levels in neonates with congenital heart diseases. Clin Chim Acta. 2011;412(23-24):2300-4. doi: 10.1016/j.cca.2011.08.030. [PubMed: 21910979]. 
24. Cantinotti M, Clerico A, Murzi M, Vittorini S, Emdin M. Clinical relevance of measurement of brain natriuretic peptide and N-terminal pro-brain natriuretic peptide in pediatric cardiology. Clin Chim Acta. 2008;390(1-2):12-22. doi: 10.1016/j.cca.2007.12.020. [PubMed: 18230356].

25. Logeart D, Thabut G, Jourdain P, Chavelas C, Beyne P, Beauvais F, et al. Predischarge B-type natriuretic peptide assay for identifying patients at high risk of re-admission after decompensated heart failure. J Am Coll Cardiol. 2004;43(4):635-41. doi: 10.1016/j.jacc.2003.09.044. [PubMed: 14975475].

26. Auerbach SR, Richmond ME, Lamour JM, Blume ED, Addonizio LJ, Shaddy RE, et al. BNP levels predict outcome in pediatric heart failure patients: post hoc analysis of the Pediatric Carvedilol Trial. Circ Heart Fail. 2010;3(5):606-11. doi: 10.1161/CIRCHEARTFAILURE.109.906875. [PubMed: 20573993].

27. Dao Q, Krishnaswamy P, Kazanegra R, Harrison A, Amirnovin R, Lenert $\mathrm{L}$, et al. Utility of B-type natriuretic peptide in the diagnosis of congestive heart failure in an urgent-care setting. $\mathrm{J} \mathrm{Am} \mathrm{Coll} \mathrm{Cardiol.}$ 2001;37(2):379-85. [PubMed: 11216950].

28. McCullough PA, Nowak RM, McCord J, Hollander JE, Herrmann HC,
Steg PG, et al. B-type natriuretic peptide and clinical judgment in emergency diagnosis of heart failure: analysis from Breathing Not Properly (BNP) Multinational Study. Circulation. 2002;106(4):416-22. [PubMed: 12135939].

29. McDonagh TA, Robb SD, Murdoch DR, Morton JJ, Ford I, Morrison CE et al. Biochemical detection of left-ventricular systolic dysfunction. Lancet. 1998;351(9095):9-13. [PubMed: 9433422].

30. Vasan RS, Benjamin EJ, Levy D. Prevalence, clinical features and prognosis of diastolic heart failure: an epidemiologic perspective. J Am Coll Cardiol. 1995;26(7):1565-74. doi: 10.1016/0735-1097(95)00381-9. [PubMed: 7594087].

31. Nagaya N, Nishikimi T, Okano Y, Uematsu M, Satoh T, Kyotani S, et al Plasma brain natriuretic peptide levels increase in proportion to the extent of right ventricular dysfunction in pulmonary hypertension. $J$ Am Coll Cardiol. 1998;31(1):202-8. [PubMed: 9426041].

32. Badesch DB, Tapson VF, McGoon MD, Brundage BH, Rubin LJ, Wigley FM, et al. Continuous intravenous epoprostenol for pulmonary hypertension due to the scleroderma spectrum of disease. A randomized, controlled trial. Ann Intern Med. 2000;132(6):425-34. [PubMed: 10733441]. 